LAWRENCE LIVERMORE NATIONAL LABORATORY
Developing Smart Seismic Arrays: A Simulation Environment, Obervational Database, and Advanced Signal Processing

P.E. Harben, D. Harris, S. Myers, S. Larsen, J. Wagoner, J. Trebes, K. Nelson

Septemeber 15, 2003 
This document was prepared as an account of work sponsored by an agency of the United States Government. Neither the United States Government nor the University of California nor any of their employees, makes any warranty, express or implied, or assumes any legal liability or responsibility for the accuracy, completeness, or usefulness of any information, apparatus, product, or process disclosed, or represents that its use would not infringe privately owned rights. Reference herein to any specific commercial product, process, or service by trade name, trademark, manufacturer, or otherwise, does not necessarily constitute or imply its endorsement, recommendation, or favoring by the United States Government or the University of California. The views and opinions of authors expressed herein do not necessarily state or reflect those of the United States Government or the University of California, and shall not be used for advertising or product endorsement purposes.

This work was performed under the auspices of the U.S. Department of Energy by University of California, Lawrence Livermore National Laboratory under Contract W-7405-Eng-48. 


\title{
Developing smart seismic arrays: A simulation environment, observational database, and advanced signal processing
}

\author{
Principal Investigator: Pl: Phil Harben (E\&E) \\ Co-investigators \\ Dave Harris (E\&E) \\ Stephen Myers (E\&E) \\ Shawn Larsen (Computations, CASE) \\ Jeff Wagoner (E\&E) \\ Jim Trebes (PAT) \\ Karl Nelson (ENG)
}

\begin{abstract}
Seismic imaging and tracking methods have intelligence and monitoring applications. Current systems, however, do not adequately calibrate or model the unknown geological heterogeneity. Current systems are also not designed for rapid data acquisition and analysis in the field. This project seeks to build the core technological capabilities coupled with innovative deployment, processing, and analysis methodologies to allow seismic methods to be effectively utilized in the applications of seismic imaging and vehicle tracking where rapid (minutes to hours) and real-time analysis is required. The goal of this project is to build capabilities in acquisition system design, utilization and in full 3D finite difference modeling as well as statistical characterization of geological heterogeneity. Such capabilities coupled with a rapid field analysis methodology based on matched field processing are applied to problems associated with surveillance, battlefield management, finding hard and deeply buried targets, and portal monitoring. This project benefits the U.S. military and intelligence community in support of LLNL's national-security mission.
\end{abstract}

FY03 was the final year of this project. In the 2.5 years this project has been active, numerous and varied developments and milestones have been accomplished. A wireless communication module for seismic data was developed to facilitate rapid seismic data acquisition and analysis. The E3D code was enhanced to include topographic effects. Codes were developed to implement the Karhunen-Loeve (K-L) statistical methodology for generating geological heterogeneity that can be utilized in E3D modeling. The matched field processing methodology applied to vehicle tracking and based on a field calibration to characterize geological heterogeneity was tested and successfully demonstrated in a tank tracking experiment at the Nevada Test Site. A 3-seismicarray vehicle tracking testbed was installed on-site at LLNL for testing real-time seismic tracking methods. A field experiment was conducted over a tunnel at the Nevada Site that quantified the tunnel reflection signal and, coupled with modeling, identified key needs and requirements in experimental layout of sensors. A large field experiment was conducted at the Lake Lynn Laboratory, a mine safety research facility in Pennsylvania, over a tunnel complex in realistic, difficult conditions. This experiment gathered the necessary data for a full 3D attempt to apply the methodology. The experiment also collected data to analyze the capabilities to detect and locate in-tunnel explosions for mine safety and other applications.

In FY03 specifically, a large and complex simulation experiment was conducted that tested the full modeling-based approach to geological characterization using E2D, the K-L statistical methodology, and matched field processing applied to tunnel detection with surface seismic sensors. The simulation validated the full methodology and the need for geological heterogeneity to be accounted for in the overall approach. The Lake Lynn site area was geologically modeled using the code Earthvision to produce a 32 million node three dimensional model grid for E3D. 
Model linking issues were resolved and a number of full 3D model runs were accomplished using shot locations that matched the data. E3D generated wavefield movies showed the reflection signal would be too small to be observed in the data due trapped and attenuated energy in the weathered layer. An analysis of the few sensors coupled to bedrock did not improve the reflection signal strength sufficiently because the shots, though buried, were within the surface layer and hence attenuated. Ability to model a complex three-dimensional geological structure and calculate synthetic seismograms that are in good agreement with actual data (especially for surface waves and below the complex weathered layer) was demonstrated. We conclude that E3D is a powerful tool for assessing the conditions under which a tunnel could be detected in a specific geological setting. Finally, the Lake Lynn tunnel explosion data were analyzed using standard array processing techniques with the result that single detonations could be detected and located but simultaneous detonations would require a strategic placement of arrays.
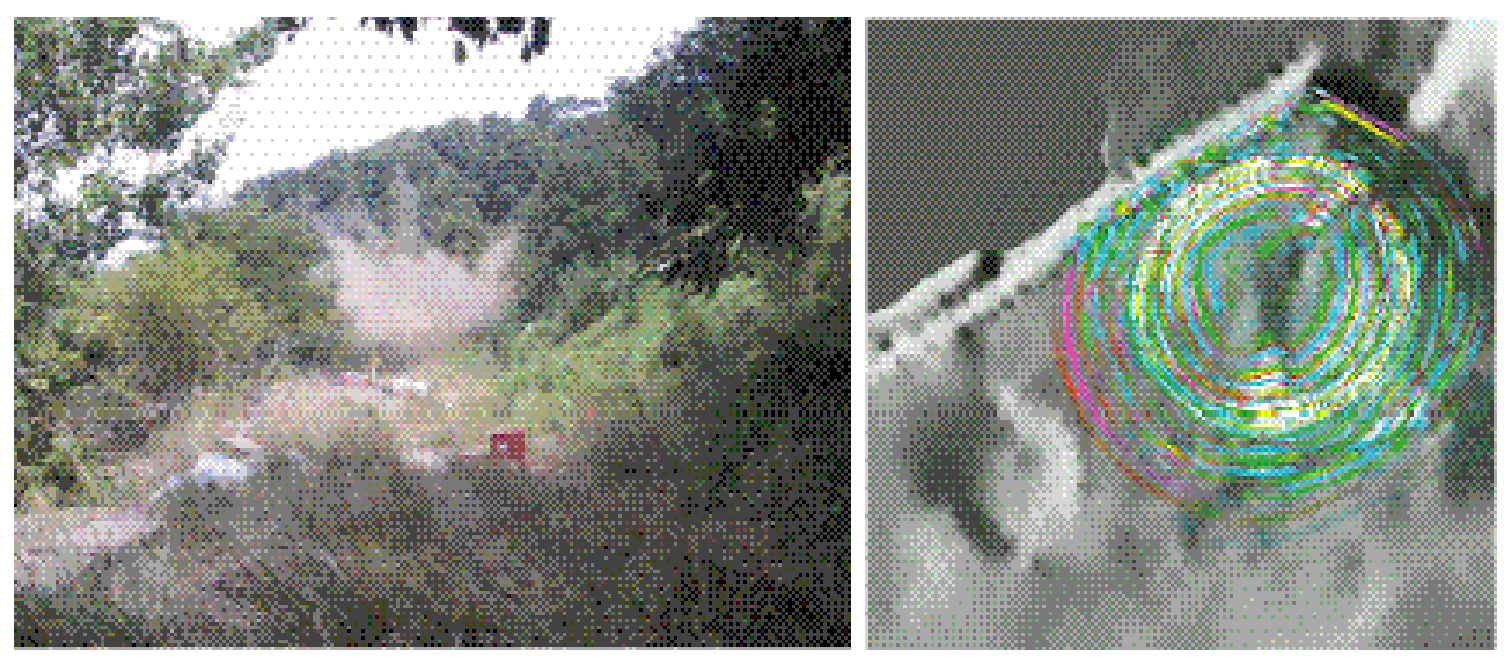

The photo on the left shows a surface seismic shot detonation at the Lake Lynn site during the field experiment. The right side image is a map view of the surface wavefield potential calculated by E3D for that explosion using the 32 million node three-dimensional geological model developed with Earthvision. In the image, P-waves are magenta, S-waves are turquoise. Simulations verify that advanced signal processing methods are required to detect and image underground facilities. 